\section{ELIMINATION OF CROSS-INFECTION} AN EXPERIMENT

BY

\author{
H. P. PICKERILL, C.B.E., M.D., M.S., F.R.A.C.S. \\ Consulting Plastic Surgeon, Wellington Hospital, N.Z.
}

AND

CECILY M. PICKERILL, M.B., Ch.B.

Acting Plastic Surgeon, Wellington Hospital, N.Z.

\begin{abstract}
"The treatment of illness in hospital rather than in the home has many advantages. It also has one serious drawback. This is the risk-sometimes slight, but in some classes of patient genuine and ever-present-of acquiring a fresh infection. To suppose that the great reforms of the latter part of the nineteenth century did away with this risk or even reduced it to minor proportions is a grave mistake. . . The danger is greatest among children." (Leading article, B.M.J., 1944, 1, 497.) "We must ask ourselves whether, even if we had the most perfect hospitals and nursing, we would wish to keep these infants for many weeks undergoing treatment, and whether that is economically and socially a sound procedure." (Dr. Donald Paterson, Proc. roy. Soc. Med., 1941, 35, 49.)
\end{abstract}

All those whose work lies among infants and children in hospitals indeed realize to the full the truth of these statements, and the kind of surgical cases with which we personally have to deal are peculiarly liable to cross-infection in hospital wards. Many years ago we realized the truth of this in respect of cleft-palate cases, in which the upper raw nasal surface is just a trap for all types of infectious organisms floating about a hospital ward, and from which cross-infection, dehiscence, and sloughs are apt to ensue. Similar cases are hypospadias, angiomata, and syndactylism; for we are firm believers in early operation in all of these-for the reasons that in infancy the patient is fully controllable by the mother, one has a comparatively passive subject to work upon, and the child grows up without any knowledge of deformity or disfigurement (a very important psychological point). All congenital deformities tend to get worse rather than better with age, and if left until later childhood the mother has lost control and there are only fear and non-cooperation on the part of the patient-factors which make plastic surgery infinitely difficult.

We determined long ago to undertake no such cases in hospital wards. For many years all such infants have been nursed by their mothers either in their own homes or elsewhere. This of itself eliminated a very large amount of cross-infectionpossibly $75 \%$-but it was not entirely satisfactory. Conditions in some of the homes were far from desirable, and occasionally some other member of the family would come home with a bad cold, resulting eventually in an infection of the baby. The parents of these babies were for some inscrutable reason nearly always impecunious, with all the resulting restrictions of facilities for nursing; they rarely had telephones, and a single room in a nursing home was quite out of the picture. Yet these babies were worth making into useful members of society. We had had very many encouraging results-and also some reverses-for once a palate, for instance, has failed, the child is often doomed to take a very back seat in life, no matter how well developed he may be mentally or physically. We seemed to have reached an impasse. We felt that there was no reason why any cleft-palate, hare-lip, or hypospadias operation for infants should ever fail, provided that the right conditions could be obtained for their treatment. What we felt was necessary was some place where mothers could stay with their babies in peace, cleanliness, and happiness, and with reasonable facilities for treatment, and where extraneous sources of cross-infection could be rigidly controlled. We sought in vain for any support for such a scheme from private, official, and philanthropic sources. Then, on the advent of. social security hospital benefits in New Zealand, we thought we saw our way to do what we wanted to do for these babies. But we did not want a hospital staffed in the usual way; we required, and insisted, that each mother must nurse her own baby with as little extraneous interference as possible. But would the Government make benefits available to these mothers? After full investigation they did; and on behalf of the mothers and babies we wish to express our thanks to the New Zealand Health Department for their wise and valuable assistance.

\section{The Scheme in Operation}

Being assured that the greater part at least of the expenses of maintenance would be found, we obtained a suburban house with a reasonable-sized garden, and proceeded to convert it into something like what we considered was necessary to fill the bill. We now have accommodation for 12 mothers and babies. Each mother with her baby has a room to herself ; some of the rooms are quite small, but all conform to the Health Department's requirements. Each has a large window facing the sun, and is daintily furnished-not at all like a hospital ward. We invite the mothers to come and nurse their babies just as if they were at home. No charge is made for maintenance, and only very occasionally are parents themselves able to pay any fees at all for treatment (some hospital boards pay very modified fees). A large workshop in the garden was converted into an isolation ward, but we have had to use it only once as such-for a mild case of chicken-pox, which did not spread. We have also built a small but very efficient theatre block in the garden. We are therefore fairly self-contained. The scheme has been in operation for three years, so that we can with fairness now perhaps estimate its value. The clinic has been full nearly the whole time, and so far there has not been a single case of cross-infection, local or general, not a single slough, not a single case of dehiscence. The worst that has happened has been the loss of a suture, and that only rarely, and no sign of what Sir W. de Courcy Wheeler called that other " bugbear of cleft-palate surgery-hyperpyrexia." There has been no failure with any cleft-palate or hypospadias case, nor loss of graft for angiomata or syndactyly. Post-operative antiseptics or sprays (beyond a little weak argyrol in the nose occasionally) are not used at all, so absence of infection cannot be due to their use. We do not claim to have reached perfection, for we are always endeavouring to better our methods and technique, but it is fairly certain that if 12 beds in a children's ward had been occupied with similar cases for three years, a considerable proportion would have been badly infected, either locally or generally, and therefore have been more or less failures. We believe that in some hospitals the infection rate is very high, though figures are difficult to obtain, and there was early last year much correspondence in the Journal about hospitals being dangerous places for infants. We therefore think that our experiment has justified itself, and we can claim to have so far eliminated the danger of hospital cross-infection in this class of case.

Other points to be noted as contributing to such results are:

1. All dressings are done in the theatre, under "theatre conditions."

2. Each baby is seen practically every day.

3. No mother or baby is permitted to come if either has a cold, and visitors are not encouraged.

4. Very great attention is paid to the feeding of the babies and to their weights. A strict rule is, "No gain in weight, no operation."

5. Mothers are encouraged to take their babies out in "prams" and to nurse them out of doors in the sunshine between operations.

6. Mothers must be kept happy. A disgruntled mother means a miserable and discontented baby, for whom any plastic operation would probably fail. This is possibly the hardest job of all, for one such mother may upset all the others. If she cannot be cured quickly (in two or three days at the most) we send her home; she comes back in a quite different frame of mind. Mostly, however, mothers are very glad of the rest and change and freedom from household cares, and co-operate splendidly in the work.

\section{Comment}

Prof. Grey Turner has recently stated (Journal, 1944, 2, 92) that in Newcastle-upon-Tyne he also used to treat as outpatients many acute surgical conditions in infants as well as hernias and cleft palates-that is to say, he relied on the nursing of the mothers. He further states: "I believe that in most cases these little ones have a better chance if dealt with in this way, for they go back to an environment to which they are accustomed, and ... receive the undivided attention of persons with whom they are thoroughly familiar." We think, though, that our plan of keeping mother and child 
together under as near ideal conditions as possible is an improvement-a step forward that is reflected in our greatly improved results during the past three years. An infant's environment is, and should be, its mother. We are using sedative drugs less and less, and of ten none at all. A baby is expected to be back on spoon feeding within eight hours of any operation.

The rationale of the whole scheme is based on the fact that a baby is born with a certain degree of passive immunity to its mother's organisms, and that it acquires further immunity in the next few months; and we endeavour to expose it to no other organisms whatever.

Since writing the foregoing account the Minister of Health has announced that in future his Department will defray the cost of treatment and maintenance of mothers and babies in our clinic.



\section{A FACULTY OF OPHTHALMOLOGISTS}

The following statement outlining a plan for the formation of a Faculty of Ophthalmologists has been received from the Council of British Ophthalmologists, whose honorary secretary is Mr. Frank W. Law, F.R.C.S.

There is obvious need for an authoritative and representative body to guide ophthalmologists through the intricate and important problems which are to be settled in the near future, to represent their interests to the State, and to co-ordinate their efforts, so that in the coming reorientation of the medical service of the country the greatest good accrues to the people, while at the same time the interests of the profession are preserved. It is generally accepted that, although circumstances may necessitate that changes be gradual, fundamental principles are now being evolved which will profoundly affect the medical profession and the community at large. So far as the ophthalmic services are concerned, the alternative to having policies imposed by others is to establish an authoritative body which will be able to initiate and criticize policy so that the interests both of the profession and of the community may be furthered.

The need for a body of this sort became apparent towards the end of the last war, and on the initiative of certain leading ophthalmic surgeons a general meeting of British ophthalmologists was held on May 2, 1918, at which it was decided to establish a Council of British Ophthalmologists, consisting of the Presidents and Past Presidents of the Ophthalmological Society of the United Kingdom and the Section of Ophthalmology of the Royal Society of Medicine, together with nine members elected annually, four each by the Councils of these bodies and one by the Council of the Oxford Congress. Later the Master and the Past Masters of the Oxford Congress were added as permanent members and the number of elected members was increased.

The functions of the Council, as stated in its rules, were "To take cognizance of, and to act in, all matters of ophthalmic interest arising in connexion with national industries and public services, and to initiate or to advise concerning movements which have for their object the welfare of the eyesight of the community." The Council of British Ophthalmologists has done much valuable work in many different fields-political, educational, and scientific; but recently it has been felt that this Council would have more weight and authority if it were more directly representative of the whole body of ophthalmologists in the country.

Some of the immediate problems which require examination and early solution are of great moment. The White Paper outlining the Government's proposal for a National Health Service deals vaguely with an ophthalmic service, although it is clear that it is the Government's intention to establish such a service. It will be the first task of the Faculty to examine the many questions arising in this connexion, and its aim, in collaboration with the appropriate Ministries and other bodies concerned, to play an important part in determining the form which this service will take. This raises questions not only of conditions of service but of the relation of the ophthalmic practitioner to the dispensing and sight-testing opticians, the methods of spectacle supply, the establishment and control of clinics, and so on, all of which are of far-reaching importance. Moreover, the institution of a National Service will raise the issue of the personnel who are to be considered as ophthalmologists, and the regionalization of hospital services will require adequate planning.

In addition to these medico-political matters it is evident that the questions of education and research, clinic and hospital policy, industrial problems, and a host of others are to assume importance in the immediate future. It is advisable that the whole body of ophthalmologists should play a part in the institution of such policies as they affect their specialty and be in possession of a mechanism to influence their development. Organizations apart from ophthalmologists are taking an interest in such questions. It would seem of importance that there should be some body more representative than the Council of British Ophthalmologists, as at present constituted, to guide the profession and advise the State. The Council of British Ophthalmologists has therefore decided to promote the formation of a Faculty of Ophthalmologists.

\section{Functions of the Faculty}

The functions of the Faculty will be:

1. To take cognizance of, and to act in, any matters of ophthalmic interest.

2. To encourage suitable standards of education in ophthalmology for undergraduate and postgraduate students.

3. To encourage research in ophthalmology and cognate subjects.

4. To secure such conditions in ophthalmic practice as will attract persons of high professional attainments and afford ample scope for the exercise of their abilities.

5. To maintain a high ethical standard in ophthalmic practice.

6. To act as an authoritative body for the purpose of consultation in matters of public and professional ophthalmic interest.

\section{Details of Constitution}

The Faculty shall consist of Members and Associates who must be registered medical practitioners and have the following qualifications :

Members.-Only ophthalmologists of full consultant status shall be eligible for membership. .They shall be: (1) Ophthalmic surgeons to hospitals recognized as schools of ophthalmology by universities or other medical examining bodies. (2) Ophthalmic surgeons other than the above who have been engaged for at least five years in full-time practice as specialists and have charge of beds in voluntary hospitals approved by the Council (at the initiation of the scheme, approved by the C.B.O.). Provisionally, these shall be general hospitals of more than 200 beds and special ophthalmic hospitals of more than 20 beds. (3) Persons no longer on the active staffs of hospitals who have held appointments specified in Classes (1) and (2). (4) Other ophthalmic surgeons of consultant rank approved by the Council, including those in the Services or holding Government appointments.

Associates.-Any ophthalmologist who has been for at least two years in full-time practice as a specialist (civilian or Service) shall be eligible for election as an Associate, on application in prescribed form and approval by the Council.

The above qualifications for Members and Associates are possibly temporary standards which may require revision in case of the establishment of a national grading of consultants and specialists.

Executive Organization.-Executive powers shall be vested in a council which, for the sake of continuity, shall be known as the Council of British Ophthalmologists. This Council shall consist of 21 members, of whom 15 shall be elected by Members and 6 by Associates of the Faculty.

Officers.-The officers of the Faculty shall be the President, VicePresident, Hon. Secretary, and Hon. Treasurer, who shall be elected annually by the Council from among its members. Election to the Council shall be by postal ballot on a national basis, but with provision as follows for regional representation. The electorate will be divided into five regions. In the case of Members, the candidate in each region who receives the highest number of votes in the national ballot shall be deemed elected as the representative of his particular region. Thereafter the remaining seats on the Council shall be filled by those other candidates receiving the highest numbers of votes in the national ballot. In the case of Associates, the candidate in each region receiving the largest number of votes in the national ballot will be deemed elected, except in the London region, where the two candidates receiving the highest number of votes will be deemed elected. As there will be five regions all the six seats open to Associate candidates. will thus be filled. One-thirc of the members of the Council shall retire each year. The members of the Council to retire in every year shall be those who have been 